Article

\title{
Online and Offline Communities in the Sharing Economy
}

\author{
Taneli Vaskelainen * and Laura Piscicelli \\ Copernicus Institute of Sustainable Development, Utrecht University, Princetonlaan 8a, \\ 3584 CB Utrecht, The Netherlands; 1.piscicelli@uu.nl \\ * Correspondence: t.vaskelainen@uu.nl; Tel.: +358-50-311-2551
}

Received: 30 June 2018; Accepted: 15 August 2018; Published: 17 August 2018

\begin{abstract}
The online community is crucial to sharing economy platforms because without it, no transactions can take place. Online communities have been studied extensively, but so far, little attention has been paid to how they link to different offline communities, such as geographic (e.g., neighborhoods) and relational communities (e.g., friends and colleagues). In this study, we address this gap by examining the importance of communities to the users and the entrepreneurs of the goods-sharing platform Ecomodo. We conduct a qualitative content analysis of archival and interview data to uncover the importance of different communities and the relationships among them. We discover that the platform design aimed to facilitate lending and borrowing in relational communities. However, geographic communities were more important to the users since most of them joined the platform to be acquainted with their neighbors. We also find that the platform entrepreneurs underestimated the behavioral changes needed to use the platform. The producers were not used to asking for money to lend their possessions, and it was difficult to teach consumers to borrow instead of buying. We use these findings to offer recommendations to practitioners and discuss some avenues for further research.
\end{abstract}

Keywords: sharing economy; collaborative consumption; sustainable business models; P2P platforms; online community; community

\section{Introduction}

Over the last decade, the rise of the sharing economy—defined by Frenken and Schor [1] (pp. 4-5) as "consumers granting each other temporary access to under-utilized assets ('idle capacity'), possibly for money"- has received growing attention because of its potential to foster more sustainable lifestyles [2]. By tapping into the excess capacity of existing goods, such as cars and houses, the sharing economy can prevent new purchases, increase resource efficiency, and reduce waste [3]. As such, the sharing economy represents a promising alternative to current unsustainable patterns of production and consumption, and its wider diffusion can accelerate the much-needed transition towards sustainability [4].

Sharing economy practices (e.g., renting, swapping, lending and borrowing) are often facilitated by digital platforms that connect individuals who offer their goods (peer providers or producers) with people (peer consumers) willing to make use of the items for a short period [5]. However, setting up and operating a successful marketplace for online sharing economy are challenging endeavors. Sharing economy platforms have to reach a critical mass of users to effectively match supply (producers) with demand (consumers) [6-8]. Moreover, interactions between producers and consumers require a significant degree of trust that platforms typically strive to create through the use of reputation systems, such as user ratings and reviews [9]. 
Building a thriving online community is key to the functioning of peer-to-peer platforms $[10,11]$. It has been found that sharing organizations use a variety of governance practices to encourage participation and strategically coordinate and control interactions in their online communities [11]. However, the different roles played by distinct communities of online users (e.g., producers, consumers) have neither been systematically recognized nor analyzed in extant research. Besides the problematic use of the term community in the existing sharing economy literature, there is also a lack of attention to offline communities and their relevance to the success of online sharing platforms.

To fill these knowledge gaps, we shed light on the under-explored process of building thriving user communities that engage in the sharing economy, with the aim of fostering sustainability. Our research question is as follows: How are different online and offline communities relevant to the functioning of sharing economy platforms? We identify five types of online and offline communities and examine their interactions in the context of a goods-sharing platform. Drawing on a variety of data sources (i.e., user interviews and archival data), our study is one of the few that considers the producer, the consumer, and the platform simultaneously. By investigating the case of an unsuccessful peer-to-peer platform, this study also contributes to the much-needed analysis of failures in the sharing economy [12] and ultimately, provides insights into the design of virtual environments as marketplaces of the sharing economy.

We have structured this paper as follows. In Section 2, we describe the different online and offline communities that are relevant to the operations of sharing economy platforms. In Section 3 , we introduce the case study and the research design that we have adopted to empirically analyze how each of these communities was accounted for in the strategy and the design of the goods-sharing platform under investigation. We present this study's results in Section 4 and use them in Section 5 to provide recommendations to sharing economy entrepreneurs. The main findings are discussed in Section 6 to elaborate on the reasons behind the platform's failure to reach a critical mass of users. In Section 7, we conclude this paper by acknowledging our study's limitations and suggesting avenues for future research.

\section{Online and Offline Communities}

Gusfield [13] identifies two uses of the term community; it can refer to a group of people living in the same geographic area (e.g., a neighborhood or a city) or to a relational community, namely, people connected by an interest or a profession (e.g., a club or a school). These two types of communities often overlap; for example, a school is usually located in a specific geographic area where teachers teach and students learn. However, relational communities do not always require geographic proximity. For example, open-source software developing communities are purely virtual communities, but their members usually feel that they are part of a community [14].

Research commonly uses the term community to indicate a group of people whose members have a sense of community, that is, individuals who share a feeling of belonging to the group, influence and are influenced by it, share a history and experiences together, and whose needs are met by being part of the group [15]. We examine communities from the sharing economy platform's perspective and therefore, use the word communities more loosely to refer to groups of people that are relevant to the functioning of the platform. For example, the hosts and the guests in Airbnb might not have a sense of community as they might just feel like customers using a service. However, from the platform's standpoint, they form an important group of people without whom the service delivery would be impossible. The users of a sharing economy service are generically referred to as its online community even though the studies about them usually do not assess if the users actually have a sense of community [16]. However, often sharing economy platforms often attempt to create a sense of belonging in their online communities [11].

The communities relevant to the sharing economy are summarized in Table 1. The online community can be divided into two groups of people-the producers and the consumers. The producers offer their items or assets in the sharing economy platforms (e.g., hosts in Airbnb), 
whereas consumers rent or use these assets (e.g., guests in Airbnb). The producers and the consumers have different interests-the former typically in making money with their assets, the latter in getting the items they need in a convenient manner [17]. However, the producers are concerned that the consumers might mishandle the borrowed assets. This situation can create mismatches between what the producers want to offer and what the consumers want to use. For example, it has been demonstrated that in a peer-to-peer lending platform, consumers are interested in borrowing expensive items, but the producers are unwilling to put these on offer because they do not feel they can trust strangers [18]. The platform entrepreneurs have to build clever design solutions to address the different interests and concerns of producers and consumers. Therefore, we observe the two user groups separately in this paper.

Table 1. Offline and online communities relevant to sharing economy platforms.

\begin{tabular}{ccc}
\hline Community & Description & Online or Offline \\
\hline Producer community & Individuals who offer their items or assets in the platform & Online \\
Consumer community & Individuals who rent or use the items available on the platform & Online \\
Geographic community & Individuals living in the same geographic area (e.g., city or neighborhood) & Offline \\
Relational community & Individuals connected by an interest or a profession (e.g., choir or school) & Offline \\
Value-based community & Individuals sharing similar values & Offline \\
\hline
\end{tabular}

In addition to the online communities of producers and consumers, several offline communities are relevant to sharing economy platforms. Geographic communities are important because, unlike many online communities, they deal with physical assets. For example, in a peer-to-peer carsharing platform, a producer and a consumer either agree on a key exchange or in a few cases, can book a car with a smart lock and fetch the car without the car owner's active participation [19]. In both cases, the car only serves a local geographic community. Convenience is important to the consumers in sharing economy platforms [17,19]; therefore, these local geographic communities are quite often much smaller units than countries or even cities. For example, the likelihood of people using a shared car drops significantly with people living more than $500 \mathrm{~m}$ away from the car [20]. This fact is known to the carsharing companies, and they try to create geographic communities around the cars. For example, the Belgian carsharing service Cozycar helps prospective users throw local parties, with the aim of introducing carsharing to their neighbors [21].

Relational offline communities can also be important to sharing economy platforms. The usually high sense of community in relational communities instills trust among community members [22]. On the other hand, in many relational communities, people are naturally geographically close to one another. Therefore, these communities can serve as auspicious environments for sharing economy platforms because they help overcome many of the barriers to the use of such platforms. Producers can offer quality assets because they trust consumers, and consumers gain easy access to the assets because of their geographic proximity. On the other hand, it is possible to imagine situations in which relational communities would benefit from sharing economy platforms. For example, schools in a city might want to pool their resources to make better use of these assets. However, they might lack the technical know-how to create a system to facilitate this sharing of goods; thus, a lending and borrowing platform could offer an easy way to do so.

A final potentially relevant offline community is a value-based community. We use the phrase to refer to a group of people in the operational area of a sharing economy platform whose members share the values of the platform or to whose values the service provided by the platform appeals to (e.g., caring for other people and the environment). This is a relevant community for a platform because meeting like-minded people has been mentioned as one reason for participating in the sharing economy $[17,23]$. Therefore, a value-based community serves as a latent community that the platform can tap into as an easily reachable customer base. 


\section{Materials and Methods}

\subsection{Ecomodo and Peer-to-Peer Lending and Borrowing Services}

To investigate the roles of different types of communities (i.e., consumer, producer, geographic, relational, and value-based) and their interplay in the context of the sharing economy, Ecomodo-a goods-sharing platform operating in the UK-was chosen as a suitable case study (Figure 1). Ecomodo was founded in 2010 and terminated its operations in 2015 due to a failure to reach a critical mass of users and stay financially viable. The platform facilitated renting, lending, and borrowing of products among its users, charging fees on monetary transactions. The fees were waived if the users decided to donate the proceeds to charity or opted for free exchanges. Ecomodo had no additional revenue streams from advertising. While it was also possible to list skills and spaces on the platform, those represented only a small portion of Ecomodo's inventory. For example, in February 2013, consumer goods accounted for over $80 \%$ of the items available on the platform. Most items were offered for a fee (69\%), 25\% for free, and 6\% for charity. The goods that were typically featured on Ecomodo ranged from ladders and do-it-yourself tools to camping gears. The wide variety of products makes Ecomodo (and its underlying business model) different from most peer-to-peer sharing platforms, which tend to focus on a single type of (and usually more expensive) asset, such as cars (e.g., carsharing platform SnappCar) and houses (e.g., Airbnb, Couchsurfing).

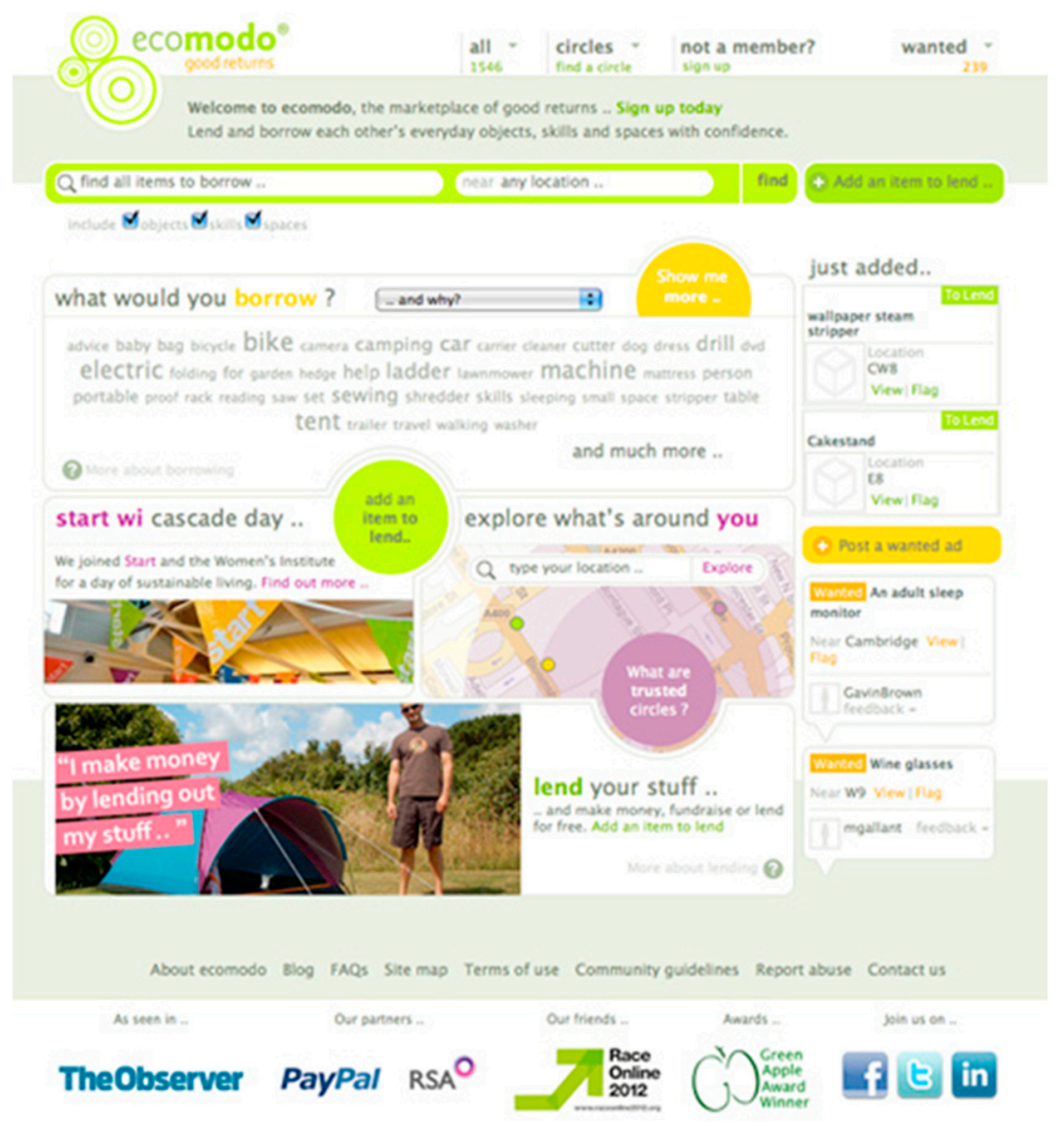

Figure 1. Ecomodo homepage.

\subsection{Data Collection}

The data sources used for this article are presented in Table 2. We collected data from both Ecomodo users and platform entrepreneurs to observe the communities from different sides. A platform could plan features that would enable the creation of communities, but in the end, the users 
would decide whether or not the features would be used. The user data consisted of 10 semi-structured interviews, which were collected from June to September 2013. The data on the platform entrepreneurs came from different archival sources, including the Ecomodo blog and web pages, as well as press articles, collected between March and May 2018. We decided to rely on archival sources because, unlike interview data, they would not be susceptible to post-hoc rationalization and impression management [24]. We did not have these problems with the user data because they were collected when the platform was still active and its members were reflecting on their behavior during that period.

Face-to-face interviews were conducted with 10 Ecomodo users (7 females and 3 males) as part of a doctoral project exploring the acceptance, adoption, and diffusion of sharing economy platforms (see [25]). All informants (irrespective of whether acting as producers, consumers, or both) were inactive on the platform (i.e., dormant users) at the time of the interview. The informants' demographic characteristics are provided in Table 3. The interview was designed to explore the informants' (i) personal values and (ii) general understanding of sharing economy practices, (iii) attitudes toward different sharing economy alternatives as opposed to private ownership, and (iv) evaluation of the Ecomodo platform. The last set of questions (Appendix A) was particularly useful for uncovering the different online and offline communities' roles in the functioning of Ecomodo. All interviews were recorded and transcribed verbatim.

Table 2. The data used for the study.

\begin{tabular}{ccc}
\hline Source of Data & Primary Purpose of the Data Source & Amount of Data \\
\hline User interviews & $\begin{array}{c}\text { To create a picture of how producers and consumers perceived } \\
\text { the importance of different online and offline communities }\end{array}$ & $\begin{array}{c}10 \text { semi-structured interviews, } \\
769 \text { min in total }\end{array}$ \\
\hline $\begin{array}{c}\text { Ecomodo blog, press articles and } \\
\text { press releases }\end{array}$ & $\begin{array}{c}\text { To understand how the platform tried to address different } \\
\text { online and offline communities }\end{array}$ & 98 blog pages, 26 press articles \\
\hline Ecomodo web pages & To thoroughly understand how the Ecomodo platform worked & 77 pages \\
\hline
\end{tabular}

Table 3. Informant demographic characteristics.

\begin{tabular}{cccccc}
\hline & Age & Marital Status & Household Income $(\boldsymbol{E})$ & Occupation & Type of User \\
\hline Amy & $25-34$ & Single & $10,000-14,999$ & Employed part-time & Producer \\
Brian & $35-44$ & Married & $45,000-54,999$ & Employed full-time & Producer/Consumer \\
Connie & $35-44$ & Married & 100,000 or more & Self-employed & Producer/Consumer \\
Emma & $66-100$ & Divorced & $20,000-24,999$ & Retired & Consumer \\
Holly & $45-54$ & Married & $55,000-99,999$ & Unemployed & Consumer \\
Isabel & $35-44$ & Married & 100,000 or more & Self-employed & Producer/Consumer \\
James & $45-54$ & Married & $55,000-99,999$ & Employed full-time & Producer \\
Linda & $25-34$ & Married & $45,000-54,999$ & Self-employed & Consumer \\
Martha & $45-54$ & Married & N/A & Employed part-time & Consumer \\
Thomas & $25-34$ & Married & $35,000-44,999$ & Employed full-time & Consumer \\
\hline
\end{tabular}

We collected the archival data by both directly downloading them from the internet and using the internet archival tool Wayback Machine. For example, the Ecomodo blog could still be found on the internet [26], and many of the press articles were still available. However, because the site had been closed in 2015, we had to retrieve much of the material from the Wayback Machine. From each page, we tried to retrieve the latest version available to ensure that we obtained the most updated information (e.g., the FAQs might have been updated as new user questions turned up). We collected the press articles and the press releases by using Ecomodo's own press room page. Of the 26 articles, 3 were Ecomodo's own press releases, and 23 were articles published in different newspapers and magazines. Altogether, 32 articles had been published, but 6 of them could not be found anymore; therefore, we ended up with 26.

Each source of archival data had a different purpose. Both the Ecomodo blog and the press articles were collected to help us understand how the platform entrepreneurs perceived the different communities and addressed them. These two data sources complemented each other. In the press articles, the entrepreneurs communicated about the big picture of the platform, including its strategy 
and mission and the reasons behind its design. In the blog, these broad lines could be observed in action, where Ecomodo communicated about the platform's campaigns, partnerships, and progress, thus informing the public how its strategy and mission were implemented in practice. The web pages further provided information on how the platform worked on a detailed level and how this was communicated to the users. Therefore, it further complemented the two other data sources by giving us a picture of how the platform looked like from a user's perspective. The site's extensive FAQ pages also helped us a lot in understanding the details of the platform design.

\subsection{Data Analysis}

We conducted a qualitative content analysis of the data [27], with the aim of coding what the different types of communities meant for different actors in Ecomodo (producers, consumers, and the platform itself). We extracted and sorted the community-relevant data into comparable boxes and compared the results to relate the different views on the topics to one another. We divided the data between us (one coded the producer data, and the other coded the consumer data). To ensure that we both understood the different types of communities in a similar manner, we developed a coding guide with examples of how different types of communities could manifest themselves in the various data sources. For example, in the user interviews, references to the introduction of Ecomodo among friends and work colleagues were considered indicative of the existence of a relational community; in the Ecomodo website and blog, references to environmental and/or social values were treated as suggestive of the platform's attempt to engage a value-based community. The coding guide also served as a basis for a preparatory discussion on the coding, where potential shortfalls and misunderstandings were settled.

As a basis for the coding guide, we used the identified relevant communities described in Table 1 . We also included 'brand community' in our coding because other studies had identified it as an important type of community [28]. However, we do not discuss the brand community in this paper because it did not turn out to be relevant in the Ecomodo case. We added 'other community' as an extra category, which was meant for communities that might have been relevant but we might have missed in our literature review. These communities were all checked at the end of the analysis. The only community that recurred in the data and was classified under the other community category (since it did not clearly belong to any other category) comprised charity groups that were discussed because Ecomodo also enabled directing rental payments to charity. However, they were not essential to the functioning of the platform. Moreover, being specific to the Ecomodo case, they are thus not discussed in this paper.

In the coding process, we included not only the quotations that referred to an existing community but also the comments that indicated the need for a community. This inclusion was especially important for the user data. For example, many producers expressed a desire to be acquainted with their neighbors. This was a significant piece of information because it indicated the geographic communities' importance to the producers even though such communities had not yet been created on the Ecomodo platform. Therefore, these kinds of statements were coded under geographic communities.

After coding the data, we cross-checked the codes. We then discussed the findings thematically and tried to make the different data sources relate to each other, that is, understand both producers' and consumers' needs and concerns in terms of the different kinds of communities and how the platform tried to address them. On the other hand, we examined what kinds of tools the platform offered to facilitate the creation of different communities and how the online community used and perceived them. Through this process, we could create a holistic picture of the communities in Ecomodo-how the platform was designed in terms of communities, what principles guided the design, how the design met the needs of the online community, and which gaps existed between the users' desires and the actual platform design. These issues are discussed next in the results section. 


\section{Results}

The concept of community was central to the design and the functioning of the Ecomodo platform. As stated in its webpage, "Ecomodo is an online community marketplace that lets you lend and borrow each other's everyday goods, skills and spaces with confidence." The platform was conceived and promoted as a natural continuation of e-commerce websites and gift-giving practices.

The principle is really that we are very good at passing on things that we are not using anymore ... but actually we've all got probably thousands of pounds worth of gear that's just sitting around that we keep because we know we need it again at some point, but it seldom gets used, it collects dust and other people could be using that ... So, Ecomodo is just a way of people seeing what's around them, so they can know where to go to borrow stuff. (BBC radio, 21 September 2010)

Nevertheless, getting people on board proved more difficult than expected. This was because using Ecomodo entailed a change in people's attitudes toward private ownership and shared access, as well as a considerable degree of trust in strangers.

But getting people to fundamentally change the way they think has been a real eye-opener... The idea of getting people to lend and borrow-especially in our society today-has been a challenge. (Southern daily echo, 8 March 2011)

Many Ecomodo users we interviewed shared a similar belief about people's reluctance to embrace lending and borrowing practices in their daily life.

I think the difficulty is that when it's not widely spread yet, so when you don't have such a broad portfolio of things that can be offered, then it's difficult for people to get into the habit of using it. But I think that conceptually it's brilliant. (Linda)

As a result of the limited number of transactions occurring on the platform, Ecomodo announced the termination of its operations in March 2015. In the remainder of this section, we elaborate on Ecomodo's producer, consumer, value-based, relational, and geographic communities to uncover how the platform addressed (or failed to address) each type of community necessary for its activity.

\subsection{Producer Community}

One of the main objectives of Ecomodo's strategy was to build its supply side by creating a large producer community and repository of available items. To recruit producers (i.e., lenders), the platform primarily tried to (i) tackle trust issues involved in lending to strangers and (ii) facilitate the process of listing goods online.

To help build trust, Ecomodo implemented "lending circles"—online groups that brought together already existing communities or people with common interests.

The team researched the barriers that stopped neighbours and friends from lending. As a result Ecomodo has some clever features to let people lend and borrow with confidence. Individuals can set up lending circles around any type of community (street, neighbourhood, school, faith centre, workplace, council, charity, community group or club) and invite people to pool their resources for the common good. People can use their circles to restrict their lending and choose to take a deposit or insurance for extra peace of mind. (Ecomodo blog post, 30 July 2010)

The lending circle feature allowed lenders to exercise more control over who could borrow their items, and it was generally well-received by the producer community.

I think the big thing to me was to be able to create circles because obviously ... I think when it comes to sharing your own things there is always concern about who you're sharing with. ... And the thing that attracted me mostly was that you had the ability to decide who you are going to share your stuff with. (Brian) 
Moreover, Ecomodo put in place some additional measures to help build trust. In particular, lenders could request a security deposit on their items and include insurance against loss or damage. Both lenders and borrowers were also able to post reviews about each other after completing transactions. Along with such a reputation system, user feedback was used by the platform as a policing mechanism to automatically suspend any unsafe or poorly described listing, as well as untrustworthy community members.

Besides addressing trust issues, a large part of Ecomodo's communication aimed at encouraging people to list their items online, as exemplified by the following blog post:

Ladders, drills and tents are the most borrowed items on Ecomodo. Got one? Why not add it to

Ecomodo to lend and choose to lend for free, a fee or for charity. (Ecomodo blog post, 18 June 2010)

However, the platform's attempt to maximize the online posting of common yet seldom-used household items (e.g., ladders, drills, and tents) seemed to partly backfire.

When I lived in Leeds there was only one person nearby [on Ecomodo]. I think I had put something like a ladder on, and they had done the same thing. So, we both had the same thing that we were lending. It didn't really help. (Conny)

Some interviewees also mentioned feeling uncomfortable with the idea of asking money for products that they would usually lend for free. Therefore, they offered their goods online free of charge or refrained from listing these altogether. However, all producers with whom we spoke-irrespective of whether or not they were charging a fee-received few requests (if any) and eventually, virtually abandoned the platform.

\subsection{Consumer Community}

Ecomodo essentially catered to its consumer community by (i) enabling searches and requests for locally available items, (ii) allowing prospective borrowers to post "wanted ads" on the platform, (iii) facilitating monetary payments (e.g., rental fees, insurance, deposits), and (iv) managing the dispute resolution process in case of damaged or unreturned items.

Despite the consumers' key role of in initiating lending and borrowing transactions, our data analysis showed that the Ecomodo management team did not necessarily treat producers and consumers as distinct communities. Nonetheless, the interviews revealed that producers might not be so keen to act as consumers, while consumers might not necessarily be interested in lending their own items through the platform.

I am more likely to lend or offer help than I am to accept help or accept lent items, I suppose. (Thomas)

Moreover, the lack of communication that specifically targeted consumers suggests that Ecomodo's founders might have assumed that demand would have automatically followed once sufficient supply had been obtained. However, such expectation somewhat underestimated the behavioral change required to shift from buying new products to borrowing used ones. Ultimately, the little uptake of Ecomodo among consumers was directly related to the limited selection of goods available online as a result of the platform's failure to attract enough producers. Similarly, most of the wanted ads that consumers posted on Ecomodo remained unfulfilled since these often concerned quite specific items (e.g., a megaphone, a puzzle-cutting machine) and the system largely relied on producers' goodwill to browse through all requests to see what items they could possibly have at home and be happy to lend.

I kind of checked fairly regularly for about six months and, like I said, I wanted a slide converter and I never [found one]. And I put out a couple of requests, and I never really got anything that was useful. (Isabel) 


\subsection{Value-Based Community}

The existence of value-based communities-comprising individuals sharing a particular set of values-was acknowledged and deeply embedded in Ecomodo's business model design. The platform tried catering to different groups of people (e.g., environmentally-motivated individuals, community-minded individuals, convenience seekers) to have the widest reach within diverse communities.

Through user-centered research we identified: the growing focus towards the environment; the increase in social values; and a move towards austerity appearing across different sectors within local communities. We choose to use these trends as an approach for a motivational model. From here, we developed the notion of lending for free, a fee or for charity as a way to reach diverse groups that can live geographically very close within our cities, towns and villages. (Ecomodo blog, 26 October 2010)

Ecomodo strongly marketed itself as a service that contributed to sustainability by providing environmental and social benefits (e.g., reducing consumption and preventing waste, helping out a neighbor or a friend). These ideas resonated with all our interviewees and motivated them to join the platform. Most of them declared to have signed up on Ecomodo to connect with their local community or "to be green."

Most people were very receptive, and a common comment was "what a great idea". A lot of people were familiar with Freegle and Freecycle and saw Ecomodo as a natural next step. We signed up 25 people to Ecomodo on the day, with lots more taking away a leaflet for more information. Even if people were visitors to Cromford they could check out what was available in their area. (Ecomodo blog, 27 July 2012)

I just liked the idea of people on a local community either hiring out or sharing things that they no longer have a daily use for. So, I thought that was a really good idea. (Emma)

However, while it seemed that belonging to a value-based community often brought users to the platform, it did not automatically translate into active participation due to the lack of convenience (e.g., availability and proximity of the items).

\subsection{Relational Community}

Relational communities-groups of friends and work colleagues-were central to Ecomodo's design by being facilitators of trust in lending and borrowing transactions.

Ecomodo is a new social enterprise with that belief at its heart. Ecomodo builds upon real life communities to create resource pools. They enable confident lending and borrowing of objects, skills and spaces within communities. Imagine the sheds, lofts, garages and cupboards of your neighbours, friends and colleagues all opened up for you to use. Imagine the range of equipment and the corresponding opportunities that would arise, without investing yourself in expensive, bulky and seldom used new equipment. (Guernsey press, 16 March 2010)

Lending circles were thought of as online embodiments of real-world communities. However, it is questionable whether Ecomodo actually offered any added value to offline relational communities since people could directly ask their friends and colleagues to lend them items without the intermediation of a platform.

I think it's really difficult to get people to lend things to people they don't know. And that's effectively what's happening in Ecomodo. That doesn't really bother me, because I have people I don't know coming and staying in my house all the time [through Airbnb] and I am quite relaxed about things, but the other people I've spoken to they don't really see the benefit: why would they have to sign up for Ecomodo while they have a group of friends they can ask if they need to borrow something? (Connie) 
The platform's formalization of everyday transactions occurring in offline communities was also perceived as inconvenient (and possibly less genuine) by some interviewees.

In [my] community, you know, I would rather give it for free than ... I wouldn't necessarily go to great lengths to actually advertise on there. (James)

\subsection{Geographic Community}

The importance of geographic communities for the functioning of Ecomodo's business model was clear to its founders from the beginning of their entrepreneurial adventure. The platform was conceived to create a hyperlocal economy by building a peer-to-peer market around the shared use of local, under-utilized resources.

You can't really [benefit from the fact that members come from all over the UK]. I mean it's used very very locally. I mean, it's all about communities; it's what you call a hyper local website, which basically means that it's using the power of the Internet, the power of the sort of global technologies, but it's actually used on a very very local level to enhance communities. So, really the only resources that are on there that are useful to people in Guernsey are the ones that are in Guernsey. So, it's developing lots of little hubs of activity. (BBC radio, 21 September 2010)

However, Ecomodo treated geographic communities in the same way as any relational community.

With such a wide range of service, we asked Ecomodo's co-founder, Tracy Currer, how the company goes about maintaining trust between its users. "On joining, people get a friend circle so when they invite friends, they'll automatically join their friends circle," said Currer. "Then they can join other circles or create their own. These can be based around a neighborhood, school, workplace or any kind of community group. Users can choose to borrow from or lend to anybody on the site, only people in their circles or just a specific circle." (Computer Shopper Magazine, January 2012)

For a geographic community to be created on Ecomodo, someone from the neighborhood needed to start a circle that others could subsequently join. This process would probably have been facilitated by the existence of some ties among neighbors. However, this was often not the case. In fact, many users joined Ecomodo and listed their belongings with the hope of being acquainted with their neighbors through their use of the platform. Thus, geographic communities (or the lack thereof) significantly contributed to the platform's failure. Ecomodo users quickly became frustrated because they were unable to find anything useful in their neighborhood and eventually abandoned the platform.

In my area I haven't seen much available. So, I've got into [Ecomodo] a couple of times, and I think there were like four or five things. And then I didn't get into it anymore. (Linda)

\section{Recommendations for Practitioners}

In this section, we lay out recommendations that are derived from the case study (Table 4) for the benefit of practitioners. We also contemplate on the relevance of the recommendations beyond the studied case.

Table 4. Recommendations for practitioners based on the Ecomodo case.

Tend to both your producers and your consumers.

Think about the added value of the platform for the different offline communities.

Do not underestimate the needed behavioral change.

\subsection{Tend to Both Your Producers and Your Consumers}

Much of the design features that Ecomodo created-lending circles, deposits, contractual structure, and insurances-were intended to create producers' trust in terms of putting their items out for lending. 
Much fewer features were created to make borrowing convenient for users. The only feature that was offered to users was the wanted ad. However, it was up to a producer to proactively browse the wanted ads and offer an item to a person who wanted to borrow one. At the end, many people were comfortable with giving out their stuff, but not many people were interested in borrowing items. In March 2015, when the company blog posted about ending its operations, 2094 products were on offer, but only one wanted ad was posted.

As mentioned in the results section, Ecomodo conducted consumer research before launching its platform. Noticing that trust was a major issue inhibiting people from lending their stuff, Ecomodo designed features to facilitate lending. However, there is little evidence that the platform entrepreneurs thought about convenience, which was central to borrowers, according to our data. People were not interested in using the platform because the things they needed were unavailable nearby. Additionally, many of the items that the producers were interested in lending out did not interest the users. For example, a lot of ladders were available on the service, but probably, people were not very interested in traveling far to get them. This set of factors links to the geographic community because to entice users, the platforms should ensure that enough items of interest are accessible within the relevant geographic community of a consumer. It seems likely that the more expensive an item, the greater the borrower's willingness to travel. However, considering that many people are unwilling to travel more than $500 \mathrm{~m}$ on foot to access a shared car [20], it is likely that all platforms need to take the geographic communities into account.

Building a sharing economy platform becomes even more challenging because not only does the platform need to build local consumer and producer communities, but these also have to be created simultaneously. As evident in our data, many of the users joined the platform and searched if there was something they needed that was available in their neighborhood, but they then forgot about the platform since they did not perceive it as useful. Therefore, it is probably essential that for most users, the platform should immediately be useful because they are unwilling to give it too many chances if they do not find (on their first few attempts) what they are looking for.

\subsection{Think about the Added Value of the Platform for the Different Offline Communities}

The Ecomodo case illustrates the importance for sharing economy platforms to understand their value to different offline communities. The company did realize that the platform was tightly tied to local communities. It stated that the users would only benefit from local products and that the trusted circles were at the center of the platform design, signaling Ecomodo's attempt to convince existing communities to join it. However, as shown in the user data, some misconceptions might have contributed to the company's failure to facilitate lending on the platform.

First, design-wise, the company did not make any distinction between relational and geographic communities. Therefore, geographic communities, such as neighborhoods, would have needed existing social cohesion to create a trusted circle. However, based on the user data, Ecomodo users perceived the platform as a tool to connect with their neighbors. Therefore, the users expected the platform to create the social cohesion required to build the circles.

Second, the company focused much of its communication on persuading existing relational communities to join Ecomodo. However, these communities did not necessarily perceive the platform's value. The users explained that usually, they first asked their friends for the items they wanted to borrow and only searched Ecomodo next. Additionally, some users mentioned that they did not like the idea of formalizing informal relationships by using such a platform. Therefore, existing relational communities might have had in place alternative ways to borrow the things they needed; thus, Ecomodo was not really interesting to them.

Peerby, a Dutch borrowing and lending platform, has a design feature to tackle the aforementioned challenges. When people want to borrow some items, their requests are automatically sent to other members in the same geographic area. The platform keeps widening a search until there is a match or 100 requests have been sent $[8,29]$. Therefore, the platform works to create links in geographic 
communities where people might not know their neighbors, thus creating value for them. This feature also probably leads to a higher amount of transactions.

\subsection{Do Not Underestimate the Needed Behavioral Change}

Ecomodo seemed to rely on people acting on their values of doing good for the community and working for sustainability. However, there seemed to be a major gap between people thinking that the platform was a good idea and they actually using it. This kind of a pattern has been noticed on a broader scale in the sharing economy. Hamari et al. [10] discovered that sustainability has a significant positive effect on people's attitude toward sharing economy platforms but no influence on their behavioral intention of using these tools. This is known in sustainable consumption research as the value-action gap; consumers' (environmental) values often do not translate into actual behavior [30].

We contextualize the value-action gap in peer-to-peer lending and borrowing platforms. The positive attitude toward the platform resulted in people joining it but not in using it in everyday transactions. This would have needed changes in the users' behavior. The behavioral change that Ecomodo focused on was about building the trust necessary for producers to lend their items on the platform. However, the user data indicated that this was not the only behavioral change needed for people to be interested in online lending and borrowing. Producers also explained that they found it odd to ask money for lending items because they were used to doing it for free. Additionally, people had to overcome their habit of buying a seldom-used item by borrowing it instead. Therefore, using Ecomodo and materializing its sustainability benefits required substantial behavioral changes among its users. It is likely that this challenge partially inhibited the platform from going viral; changing routines and behavioral patterns would take time.

\section{Discussion}

The Ecomodo case raises the question of whether or not it is possible to build an economically viable for-profit lending and borrowing platform. The challenges are daunting. The platform should teach its producers to trust it and to ask money for lending that is usually done for free. The consumers have to be taught to search the platform first before buying an item. Considering how easy buying is, this challenge by itself is a substantial one to overcome [31]. Meanwhile, the platform needs to ensure that both its producer and consumer bases are growing simultaneously in the same geographic areas (preferably neighborhoods) and that the items that people want to lend are also those that people want to borrow. Considering the myriad problems, it is unsurprising that many of the early lending and borrowing platforms have not survived. Besides Ecomodo, Crowd Rent, Share Some Sugar, Thingloop, OhSoWe, and SnapGoods have been forced to end their operations [32]. Nevertheless, some new players in the market aim for growth. Recently, the aforementioned Dutch lending and borrowing platform Peerby raised $\$ 2.2$ million in a crowdfunding campaign, and Fat Lama, a similar platform operating in the USA and the UK, received over $\$ 10$ million in venture capital money [33,34]. Time will tell if the other platforms' challenges will be overcome by a clever platform design and if the opportunity is right for people to start using the platforms on a larger scale.

It seems the chances of survival are significantly higher among companies that focus on sharing platforms for one type of expensive asset, such as cars or homes. It is difficult to claim anything certain about the profitability of a peer-to-peer car rental because many of the companies are in their growth stages and have been granted large sums of venture capital money. However, the companies have reported rapidly increasing revenues [35]; for example, in the US, the fast growth in the peer-to-peer carsharing segment has been noted [36]. In the homesharing sector, the market leader Airbnb has not only reached profitability [37], but its business is booming as well; it beats the largest hotel chains in both the number of listings and market valuation [38]. 
One reason for the higher success of homesharing and carsharing companies compared with lending and borrowing platforms is probably the fact that the carsharing and the homesharing suppliers are actually earning money. For instance, the main motivation of suppliers in peer-to-peer carsharing has been reported to be economically driven; car owners want to make money with their under-utilized assets $[36,39]$. Considering the Ecomodo case, it would seem unlikely that people could have earned large sums of money by lending mundane objects, such as ladders, so the motivation to work as a supplier relied mainly on people's willingness to contribute to environmental sustainability. Although this aim led people to join the platform, it seemed that it did not translate into significant efforts to use the platform.

However, other factors probably contribute to the success of carsharing and homesharing platforms besides earning possibilities. The required behavioral changes on the consumer side are unlikely to be as significant as they are with borrowing and lending platforms. People who need an item have to develop the habit of browsing the platform first before buying the product. With carsharing and homesharing, many people are already used to resorting to similar services, such as booking accommodations when traveling abroad or renting a car for occasional use. Peer-to-peer carsharing companies have themselves enforced this habitual link by presenting themselves as less costly alternatives to car rentals [40].

If people's existing habits explain part of the success of sharing economy platforms, it does not reflect well on the sustainability promises of the sharing economy. For example, if peer-to-peer carsharing is used mainly to replace car rental services, the service does not significantly change people's modes of mobility and therefore does not increase sustainable consumption patterns. So far, the indicative results on the sustainability effects of peer-to-peer carsharing support this argument by showing minor behavioral changes in terms of the number of kilometers driven with a car $[19,23]$. This stands in contrast to the older business-to-consumer (B2C) carsharing services, whose effects on mobility behavior have been demonstrated in many studies; joining a carsharing scheme significantly reduces the mileage driven with private cars and the carbon footprints of the users [41,42]. This difference might be due to the fact that many of the B2C services are designed in a way that makes them replacements for private cars [43]. However, this effect also hampers their growth because users' behavioral patterns are slow to change [44].

Täusher and Kiezmann [12] have identified the high costs of developing supply and demand because of the need to change consumer behavior as one of the reasons for the failure of some sharing economy platforms. We further elaborate on this argument. The sharing economy platforms serving in different sectors must approach the geographic element of supply and demand with different strategies. Lending and borrowing and carsharing platforms have to ensure the geographic proximity between producers and consumers; otherwise, transactions cannot occur [45]. Homesharing platforms most likely function the other way around; they are mainly used to book accommodations in foreign countries and cities. Therefore, the consumers do not look for rental places close to home but in distant geographic regions. Therefore, for these platforms, it is important to acquire suppliers from as many cities and countries as possible because it increases the value of the platforms. Accommodations for different trips can be booked by using the same platform with a familiar user interface, and the user profile accumulates its digital reputation through the platform's feedback system. These mechanisms are commonly referred to as network effects; each new person on the network increases its value for other people in it.

Interestingly, although geographic communities are not important for creating transactions in homesharing, these platforms have facilitated the creation of such communities. Airbnb creates local communities in the cities where it operates [46], and Couchsurfing organizes local member gatherings [47]. It is not perfectly clear why homesharing platforms are interested in geographic communities. It has been shown that participating in the gatherings positively correlates to the sense of community among the platform users [47]. However, research on the importance of the sense of community in motivating people to use sharing economy platforms is controversial. Some studies 
have found that this factor does motivate users $[17,23]$, several have noted that the motivation varies across platforms [48], and others have reported that communality is not important and even unwanted by the users [49].

The controversies in terms of the significance of consumers lead us to our first suggestion for further research: more studies should be conducted on the meaning of the communities to different kinds of platform entrepreneurs and users. In terms of users, studies using vast empirical settings spanning countries, platforms, and user roles (producer or consumer) would be useful in explaining which factors account for the importance of communities. One working hypothesis might be that the sense of community and doing good works are more important to producers than to consumers. Many studies have documented the significance of these values among producers $[17,23,39]$, whereas consumers have often been demonstrated to be motivated primarily by personal enjoyment and economic factors $[10,48,49]$. Additionally, the platforms' interest in facilitating communality should be studied. One possible explanation here is that platforms try to create lock-ins with producers, which has been documented as an important factor for the sharing economy platform's survival [12]. However, it is easy to imagine alternative explanations as well. For example, it has been suggested that many sharing economy platforms emphasize environmental and communal values to convince regulators of their positive societal effects [50,51].

Another potential avenue for further research stemming from our study comprises the behavioral and the routine aspects of using sharing services. It is well recognized in the scientific community that using sharing economy platforms requires new mechanisms of building trust among users who have not known one another beforehand [52-54]. However, as demonstrated in our study, the behavioral and the routine changes are central to the success of the sharing economy platforms as well. Research on understanding such changes has also been suggested by earlier studies [55] but has rarely been addressed [56]. This issue seems especially important when thinking about the sustainability of the sharing economy. Services that could have a significant effect on sustainability probably require changes in people's behavior (e.g., from buying to borrowing) but suffer from a much slower adoption rate compared with those that serve existing behavioral patterns. Therefore, research on how these behavioral changes could be facilitated could significantly help sharing economy services deliver on their sustainability promises.

It would also be valuable to know whether some communities are unwanted by the sharing economy platforms. Communities are usually framed as being positive contributors to these platforms, but it is easy to imagine situations where the creation of certain communities might not have beneficial effects on the platforms. For example, strong geographic communities can exit to create their own platforms. This phenomenon happened to the recycling platform Freecycle from the US, where a large segment of the UK user community broke away from Freecycle to found their own platform called Freegle because they disagreed with Freecycle's management [57].

Finally, we are calling for research that observes the sharing economy from different sides of the platform simultaneously. Usually, studies examine either the consumers [48] or the producers [39] or the platform itself [11]. Apart from our study, only a few others have taken a multifaceted view on the platforms [17]. However, investigating the different sides simultaneously can answer many practice-relevant questions. Do the design efforts of the platforms achieve their aims? How do the needs and the wants of the producers and the consumers meet, and how can the platforms address the differences? How do the goals of the online community and the platform entrepreneur differ, and what kinds of issues arise from the differences? Answering these questions could significantly help in designing better platforms and provide insights on why some platforms succeed and others fail.

\section{Limitations}

The most significant limitations of this study stem from the fact that we have only 10 user interviews, which represent a small percentage of all users of the Ecomodo platform. Therefore, we do not know to what extent the interviewed users' comments are representative of those of the whole 
population. Moreover, we do not claim that we have captured the significance of the communities for Ecomodo users entirely or have comprehensively explained the reason for the platform's failure. Instead, we have illustrated some of the issues emerging between a lending and borrowing platform such as Ecomodo and online and offline communities. With these observations, we have offered insights into the problems with making such a sharing economy platform economically sustainable. Another limitation arises from the fact that we have studied a single platform. Although we do not claim that our findings are representative of (or generalizable to) all sharing economy platforms, many of the uncovered issues concerning communities are not unique to Ecomodo. Thus, our findings could contribute to better research designs in the future.

Author Contributions: Conceptualization, T.V. and L.P.; Methodology, T.V. and L.P.; Formal Analysis, T.V. and L.P.; Writing-Original Draft Preparation, T.V. and L.P.; Writing-Review \& Editing, T.V. and L.P.

Funding: This research received no external funding.

Conflicts of Interest: The authors declare no conflict of interest.

\section{Appendix A}

Interview Guide-Part IV (Ecomodo)

- Could you tell me when and how you first heard about Ecomodo?

- Could you describe the motivations that led you to join Ecomodo?

- Have your initial expectations been met?

- What were, if any, the main uncertainties and barriers you faced in making the decision to join Ecomodo?

- What positively influenced and contributed to your decision to join Ecomodo?

- What kinds of people do you imagine are using Ecomodo?

- How often do you use the Ecomodo website and for what purposes?

- Have you already borrowed something through Ecomodo? Is there any reason for that?

- What items might you be happy to lend through Ecomodo? Is there a particular reason for that?

- How do you imagine the experience of lending and borrowing through Ecomodo would be?

- What would possibly be the positive outcomes for you of lending and borrowing through Ecomodo?

- What might be the possible drawbacks?

- Overall, how do you evaluate a service such as Ecomodo?

\section{References}

1. Frenken, K.; Schor, J. Putting the sharing economy into perspective. Environ. Innov. Soc. Transit. 2017, 23, 3-10. [CrossRef]

2. Mont, O.; Neuvonen, A.; Lähteenoja, S. Sustainable lifestyles 2050: Stakeholder visions, emerging practices and future research. J. Clean. Prod. 2014, 63, 24-32. [CrossRef]

3. Leismann, K.; Schmitt, M.; Rohn, H.; Baedeker, C. Collaborative consumption: Towards a resource-saving consumption culture. Resources 2013, 2, 184-203. [CrossRef]

4. Heinrichs, H. Sharing economy: A potential new pathway to sustainability. GAIA Ecol. Perspect. Sci. Soc. 2013, 22, 228-231. [CrossRef]

5. Cusumano, M.A. How traditional firms must compete in the sharing economy. Commun. ACM 2014, 58, 32-34. [CrossRef]

6. Hagiu, A.; Rothman, S. Network effects aren't enough: The hidden traps in building an online marketplace. Harv. Bus. Rev. 2016, 94, 65-71.

7. Eisenmann, T.; Parker, G.; Alstyne, V.M.W. Strategies for two-sided markets. Harv. Bus. Rev. 2006, 84, 92-101. [CrossRef] 
8. Piscicelli, L.; Ludden, G.D.S.; Cooper, T. What makes a sustainable business model successful? An empirical comparison of two peer-to-peer goods-sharing platforms. J. Clean. Prod. 2018, 172, 4580-4591. [CrossRef]

9. Belk, R. You are what you can access: Sharing and collaborative consumption online. J. Bus. Res. 2014, 67, 1595-1600. [CrossRef]

10. Hamari, J.; Sjöklint, M.; Ukkonen, A. The sharing economy: Why people participate in collaborative consumption. J. Assoc. Inf. Sci. Technol. 2016, 67, 2047-2059. [CrossRef]

11. Reischauer, G.; Mair, J. How organizations strategically govern online communities: Lessons from the sharing economy. Acad. Manag. Discov. 2018. [CrossRef]

12. Täuscher, K.; Kietzmann, J. Learning from failures in the sharing economy. MIS Q. Exec. 2017, 16, $253-264$.

13. Gusfield, J.R. Community: A Critical Response; Harper \& Row: New York, NY, USA, 1975; ISBN 978-0060906429.

14. Hars, A.; Ou, S. Working for free? Motivations for participating in open-source projects. Int. J. Electron. Commer. 2002, 6, 25-39. [CrossRef]

15. McMillan, D.W.; Chavis, D.M. Sense of community: A definition and theory. J. Community Psychol. 1986, 14, 6-23. [CrossRef]

16. Hartl, B.; Hofmann, E.; Kirchler, E. Do we need rules for "what's mine is yours"? Governance in collaborative consumption communities. J. Bus. Res. 2016, 69, 2756-2763. [CrossRef]

17. Bellotti, V.; Ambard, A.; Turner, D.; Gossmann, C.; Demkova, K.; Carroll, J.M. A muddle of models of motivation for using peer-to-peer economy systems. In Proceedings of the CHI '15-Proceedings of the 33rd Annual ACM Conference on Human Factors in Computing Systems, Seoul, Korea, 18-23 April 2015; pp. 1085-1094.

18. McLachlan, R.; Opila, C.; Shah, N.; Sun, E.; Naaman, M. You can't always get what you want: Challenges in P2P resource sharing. In Proceedings of the 2016 CHI Conference Extended Abstracts on Human Factors in Computing Systems, San Jose, CA, USA, 7-12 May 2016; pp. 1301-1307.

19. Shaheen, S.; Martin, E.; Bansal, A. Peer-To-Peer (P2P) Carsharing: Understanding Early Markets, Social Dynamics, and Behavioral Impacts; UC Berkeley: Berkeley, CA, USA, 2018.

20. Bundesverband CarSharing e.V.; Loose, W. The State of European Car-Sharing_Final Report D 2.4 Work Package 2; European Commission Grant Agreement No. IEE/07/696/SI2.499387; Bundesverband CarSharing e.V.: Freiburg, Germany, 2010.

21. Cozycar Organiseer een Autodeelparty! Available online: www.cozycar.be/home/autodeelparty (accessed on 13 August 2018).

22. McMillan, D.W. Sense of community. J. Community Psychol. 1996, 24, 315-325. [CrossRef]

23. Dill, J.; Mcneil, N.; Howland, S. Peer-to-Peer Carsharing: Short-Term Effects on Travel Behavior in Portland, OR; Portland State University: Portland, OR, USA, 2017.

24. Eisenhardt, K.M.; Graebner, M.E. Theory building from cases: Opportunities and challenges. Acad. Manag. J. 2007, 50, 25-32. [CrossRef]

25. Piscicelli, L. Do I Share Because I Care? The Role of Values in the Acceptance, Adoption and Diffusion of Collaborative Consumption. Ph.D. Thesis, Nottingham Trent University, Nottingham, UK, 2016.

26. Ecomodo Ecomodo's Blog I Good Returns. Available online: https:/ / ecomodo.wordpress.com (accessed on 13 August 2018).

27. Krippendorf, K. Content Analysis: An Introduction to Its Methodology, 2nd ed.; Sage: Thousand Oaks, CA, USA, 2004; ISBN 9781118541555.

28. Muniz, A.M.J.; O'Guinn, T.C. Brand community. J. Consum. Res. 2001, 27, 412-432. [CrossRef]

29. Peerby PeerbylHow Many People Does My Request Reach? Available online: https://peerby. desk.com/customer/en/portal/articles/1497089-how-many-people-does-my-request-reach- (accessed on 13 August 2018).

30. Kollmuss, A.; Agyeman, J. Mind the gap: Why do people behave environmentally and what are the barriers to pro-environmental behaviour? Environ. Educ. Res. 2002, 8, 239-260. [CrossRef]

31. Kessler, S. The "Sharing Economy" Is Dead, and We Killed It. Available online: www.fastcompany.com/ 3050775/the-sharing-economy-is-dead-and-we-killed-it (accessed on 13 August 2018).

32. Horgan, C. There Is No Share Economy. Let's Stop Pretending It Exists. Available online: https://medium. com/@cfhorgan/there-is-no-share-economy-let-s-stop-pretending-it-exists-64135056852b (accessed on 13 August 2018). 
33. Peerby Startup Peerby Raises $\$ 2.2$ Million from Users-Peerby International News. Available online: http: / / press.peerby.com/125333-startup-peerby-raises-2-2-million-from-users (accessed on 13 August 2018).

34. Knowles, K. Fat Lama: The "Airbnb for Renting Almost Anything" Raises \$10 Million. Available online: https: / / www.forbes.com/sites / kittyknowles/2018/04/25/fat-lama-the-airbnb-for-renting-almostanything-raises-10-million/\#583db0aeb7be (accessed on 13 August 2018).

35. Dickey, M.R. Getaround's Revenue Has Doubled to "Tens of Millions" in the Last Six Months. Available online: https:/ / techcrunch.com/2015/09/28/getaround-revenue-2015/?guccounter=1 (accessed on 13 August 2018).

36. Shaheen, S.; Cohen, A.; Jaffee, M. Innovative Mobility: Carsharing Outlook; UC Berkeley, Institute of Transportation Studies (UCB): Berkeley, CA, USA, 2018.

37. Hook, L. Airbnb Marks First Full Year of Profitability in 2017. Available online: https://www.ft.com/ content/96215e16-0201-11e8-9650-9c0ad2d7c5b5 (accessed on 13 August 2018).

38. Yonggui, W.; Chen, W.; Lieberman, M.; Markman, G. Special Issue Call for Papers: Challenges and Opportunities in the Sharing Economy. 2017. Available online: http://www.socadms.org.uk/specialissue-call-papers-challenges-opportunities-sharing-economy/ (accessed on 16 August 2018).

39. Wilhelms, M.-P.; Henkel, S.; Falk, T. To earn is not enough: A means-end analysis to uncover peer-providers' participation motives in peer-to-peer carsharing. Technol. Forecast. Soc. Chang. 2017, 125, 38-47. [CrossRef]

40. Spiegel Online Start-Up versus Autoverleih: GERICHT Verbietet Werbe-Attacke auf Sixt. Available online: http:/ / www.spiegel.de/wirtschaft/unternehmen/sixt-stoppt-werbekampagne-von-start-up-a843871.html (accessed on 13 August 2018).

41. Nijland, H.; van Meerkerk, J. Mobility and environmental impacts of car sharing in The Netherlands. Environ. Innov. Soc. Trans. 2017, 23, 84-91. [CrossRef]

42. Chen, T.D.; Kockelman, K.M. Carsharing's life-cycle impacts on energy use and greenhouse gas emissions. Transp. Res. Part D Transp. Environ. 2016, 47, 276-284. [CrossRef]

43. Bundesverband CarSharing bcs Stellt Nationalen Entwicklungsplan CarSharing vor. Available online: https:/ / carsharing.de/themen/politik/bcs-stellt-nationalen-entwicklungsplan-carsharing (accessed on 13 August 2018).

44. Brenner, J. Carsharing: Surfen, Klicken, Auto Fahren. Available online: https://www.zeit.de/auto/2011-03/ carsharing-zukunft-grenzen (accessed on 13 August 2018).

45. Münzel, K.; Boon, W.; Frenken, K.; Vaskelainen, T. Carsharing business models in Germany: Characteristics, success and future prospects. Inf. Syst. E Bus. Manag. 2018, 16, 271-291. [CrossRef]

46. Airbnb Cities-Airbnb Community. Available online: https://community.withairbnb.com/t5/Cities/ct-p/ cities (accessed on 13 August 2018).

47. Rosen, D.; Lafontaine, P.R.; Hendrickson, B. Couchsurfing: Belonging and trust in a globally cooperative online social network. New Media Soc. 2011, 13, 981-998. [CrossRef]

48. Möhlmann, M. Collaborative consumption: Determinants of satisfaction and the likelihood of using a sharing economy option again. J. Consum. Behav. 2015, 14, 193-207. [CrossRef]

49. Bardhi, F.; Eckhardt, G.M. Access-based consumption: The case of car sharing. J. Consum. Res. 2012, 39, 881-898. [CrossRef]

50. Slee, T. What's Yours Is Mine: Against the Sharing Economy; Or Books: New York, NY, USA, 2016; ISBN 978-1-682191-20-0.

51. Grinevich, V.; Huber, F.; Karataş-Özkan, M.; Yavuz, Ç. Green entrepreneurship in the sharing economy: Utilising multiplicity of institutional logics. Small Bus. Econ. 2017, 1-18. [CrossRef]

52. Qiu, W.; Parigi, P.; Abrahao, B. More stars or more reviews? Differential effects of reputation on trust in the sharing economy. In Proceedings of the CHI 2018, Montreal, QC, Canada, 21-26 April 2018.

53. Ert, E.; Fleischer, A.; Magen, N. Trust and reputation in the sharing economy: The role of personal photos in Airbnb. Tour. Manag. 2016, 55, 62-73. [CrossRef]

54. Chica, M.; Chiong, R.; Adam, M.T.P.; Damas, S.; Teubner, T. An evolutionary trust game for the sharing economy. In Proceedings of the 2017 IEEE Congress on Evolutionary Computation (CEC), San Sebastian, Spain, 5-8 June 2017; pp. 2510-2517.

55. Suhonen, E.; Lampinen, A.; Cheshire, C.; Antin, J. Everyday favors: A case study of a local online gift exchange system. In Proceedings of the GROUP '10 16th ACM International Conference on Supporting Group Work, Sanibel Island, FL, USA, 7-10 November 2010; pp. 11-20. 
56. Le Vine, S.; Lee-Gosselin, M.; Sivakumar, A.; Polak, J. A new approach to predict the market and impacts of round-trip and point-to-point carsharing systems: Case study of London. Transp. Res. Part D Transp. Environ. 2014, 32, 218-229. [CrossRef]

57. Lewis, S. What Went Wrong with Freecycle in the UK? Available online: https://theecologist.org/2009/sep/ 30/what-went-wrong-freecycle-uk (accessed on 13 August 2018). 